\title{
SYMPOSIUM
}

\section{Heterosexual outbreak of infectious syphilis: epidemiological and ethnographic analysis and implications for control}

\author{
D M Patrick, M L Rekart, A Jolly, S Mak, M Tyndall, J Maginley, E Wong, T Wong, \\ H Jones, C Montgomery, R C Brunham
}

This study describes the epidemiology and ethnography of an outbreak of infectious syphilis in Vancouver, British Columbia. Between 1996 and 1999, British Columbias's rate of infectious syphilis rose from 0.5 to 3.4 per 100000 , with a dense concentration of cases among sex trade workers, their clients, and street-involved people in the downtown eastside area of Vancouver. Sexual networks were imported cases with secondary spread (dyads and triads), large densely connected dendritic networks of sex trade workers and clients, or occasional starburst networks among gay men. Only 232 of 429 partners were documented as having been treated $(54 \%$ of those named, or 0.9 per case). The geographical and demographic concentration of this outbreak led to consideration of a programme of focused mass treatment with single dose azithromycin.

See end of article for authors' affiliations

Correspondence to: Dr David M Patrick, UBC Centre for Disease Control, 655 West 12 Ave, Vancouver, Canada BC V5Z 4R4; david.patrick@ bccdc.hnet.bc.ca

Accepted 6 December 2001
B tween 1992 and 1996 in British Columbia, Canada, the rate of infectious syphilis was less than 0.5 per 100000 population. ${ }^{1}$ During that interval, approximately two thirds of the 15 to 20 cases reported annually were acquired overseas, suggesting that most cases were imported or within one generation of transmission. Syphilis did not appear to be endemically rooted within British Columbia.

Beginning in July 1997 we experienced a marked increase in infectious syphilis which proved refractory to public health interventions over a 2.5 year period. In this paper we describe the outbreak and its ethnographic context, and explain the rationale for considering a novel approach to epidemic intervention-a syphilis mass treatment and prophylaxis initiative (SMTPI) using single dose azithromycin.

\section{METHODS}

Population and health indicator data were obtained from British Columbia and Canadian government sources. Trends on drug use and a description of the drug using population were obtained from an analysis of the Vancouver injection drug user study. Follow up of subjects in this cohort has been described previously. ${ }^{2}$

Laboratory and clinical reports of infectious syphilis and other STDs were received, managed, and analysed at the British Columbia Centre for Disease Control (BCCDC) in Vancouver. To supplement routine demographic data from infectious syphilis reports, an intensive case note review of all cases of infectious syphilis diagnosed between July 1997 and December 1999 was conducted. Data were entered into an automated case management and surveillance system ${ }^{3}$ and analysed using Excel, SPSS, and ArcView. Mapping was performed for those cases where there was a record of postal code. The postal code of the patient's address was used where available. In all other cases, the postal code of the clinic or physician's office where the patient had presented was used. Datapoints on the map were randomly offset by 100 metres to protect confidentiality.

Data on partner notification of infectious syphilis cases were reviewed in order to describe the structure of sexual networks in which syphilis was being transmitted. Two methods were employed to construct the networks. Initially each index record was reviewed for sex partners of the client. These partners were identified as contacts named by the client, as those who had originally named the current client, or from the comments section at the end of each client's record. The resulting list included the identifying case number of the client together with all the named contacts. Contacts were included in network analysis even when minimal locating and identifying information was available.

\section{RESULTS}

\section{Epidemiological and social context}

The downtown eastside area of Vancouver has a socioeconomic and demographic structure that differs markedly from other areas of the city and province. These determinants appear to create conditions conducive to the spread of infectious diseases of several transmission classes. The neighbourhood has experienced recent outbreaks of hepatitis B, HIV, hepatitis C, hepatitis A, and drug overdose deaths, and is the geographical centre for illicit drug use in the city. ${ }^{24}$

The estimated year 2000 population of Vancouver's downtown eastside was $53386 .{ }^{5}$ Males outnumber females except below the age of 25 and among the elderly. An estimated 11700 injecting drug users live in the greater Vancouver urban region, with approximately 8000 living in Vancouver itself. ${ }^{6}$ Key health indicators are given in table 1. Diminished life expectancy is documented in 
Table 1 Health indicators: downtown eastside compared with Vancouver and British Columbia

\begin{tabular}{|c|c|c|c|}
\hline & $\begin{array}{l}\text { Downtown } \\
\text { eastside }\end{array}$ & Vancouver & $\begin{array}{l}\text { British } \\
\text { Columbia }\end{array}$ \\
\hline Population (1999) & 52937 & 570815 & 4045661 \\
\hline Population per $\mathrm{km}^{2}$ & & 5047 & 4.5 \\
\hline $\begin{array}{l}\text { Per cent of population below low income cut off } \\
\text { (1996 census) }\end{array}$ & 51.8 & 29.9 & 19.6 \\
\hline $\begin{array}{l}\text { Per cent of population }<65 \text { receiving BC benefits } \\
1999\end{array}$ & $19.3 \%$ & $6.8 \%$ & $6.1 \%$ \\
\hline Crime rate (1998) per 1000 population & - & 154.8 & 121.5 \\
\hline $\begin{array}{l}\text { Per cent of those aged } 15 \text { and over who left school } \\
\text { before 9th grade completion (1996 census) }\end{array}$ & $18.5 \%$ & $9.4 \%$ & $7.4 \%$ \\
\hline $\begin{array}{l}\text { Per cent of rented housing } \\
\text { Life expectancy at birth } 1998\end{array}$ & - & $70.4 \%$ & $34.6 \%$ \\
\hline Male & 65.0 & 74.1 & 76.0 \\
\hline Female & 77.7 & 82.1 & 81.6 \\
\hline $\begin{array}{l}\text { Teenage births per } 1000 \text { female population aged } 15 \\
\text { to } 19,1998\end{array}$ & 29.6 & 8.5 & 18.0 \\
\hline Standardised mortality ratio, 1998 & 1.66 & 1.03 & - \\
\hline Standardised Person years of life lost ratio, 1998 & 4.06 & 1.12 & - \\
\hline Alcohol related mortality per 1000, 1998 & 2.78 & 0.7 & 0.5 \\
\hline Drug related mortality per 1000, 1998 & 1.44 & 0.3 & 0.1 \\
\hline \multicolumn{4}{|l|}{ Communicable diseases 1999} \\
\hline Gonorrhoea & - & 74.4 & 21.7 \\
\hline Chlamydia & - & 230.2 & 132.4 \\
\hline
\end{tabular}

the downtown eastside neighbourhood and relates to substantially increased mortality among injecting drug users. One hundred and five of 1416 Vancouver injection drug users study (VIDUS) subjects enrolled since 1996 have died, largely from such causes as overdose, accidents, and HIV and other infectious diseases.

A series of structural issues appears to be contributing to poor health in this community. ${ }^{7}$ Development in Vancouver during the 1990s resulted in a loss of affordable low income housing, with a concentration of the remaining units in the downtown eastside of Vancouver. Concurrently, various institutions for people with chronic mental illnesses were closed, which resulted in a rise in the number of homeless persons living in this area of the city, putting added strain on community resources.

Vancouver has long been a destination of choice for streetinvolved people from across British Columbia and Canada, and there is movement of aboriginal persons between the downtown eastside neighbourhood and aboriginal reserves located elsewhere in the province. Eleven per cent of VIDUS participants recruited in 1996/97 had moved from the greater Vancouver area by 2000. Ethnic and cultural mixing between aboriginals, white Canadians, recent Hispanic immigrants, and other groups occurs in the downtown eastside. Of VIDUS subjects, $60 \%$ are white, $25 \%$ aboriginal, $6 \%$ Hispanic, and $9 \%$ of other ethnicity.

Many people live in areas connected to the downtown eastside by transit routes but access drugs or engage in other activities in the neighbourhood. Sex trade workers in the downtown eastside are commonly drug addicted, HIV positive, and unable or unwilling to cease commercial sex activity. Fully $49 \%$ of injecting drug using women in the VIDUS study reported 100 or more lifetime partners, a conservative surrogate marker for sex trade participation.

While many sex trade clients also have addiction problems, there are suburban males who purchase sex in the downtown eastside. In recent years, examples of concurrent syphilis and HIV co-infection have been documented among this group. Moreover, between 1 July 1997 and 31 December 1999, 15 newly diagnosed HIV infections were documented in men whose sole identified risk was frequenting a sex trade worker.
Though this category had been monitored before July 1997, no cases were identified before the syphilis outbreak.

\section{Health and welfare infrastructure}

The area is serviced by two clinics-a dedicated public sexually transmitted disease (STD) clinic, and several private practices which have a focus on addiction treatment. A street outreach nursing service was instituted in Vancouver in 1988. These public health nurses provide preventive and clinical STD services directly to high risk street-involved clients. Specific thrusts included storefront clinics with mobile outreach to the gay community, injection drug users, sex trade workers, and street youngsters. By 1999, the service had grown to 15 nurses with support staff. Over a dozen community agencies also provide a variety of outreach services. These include a large needle exchange service operative since 1989, and specific community agencies aimed at single mothers, street youngsters, sex trade workers, transsexuals, Hispanic immigrants, and other groups. Peer education has been actively encouraged for more than a decade. Independent community organisations have set up successful programmes for men who have sex with men. There are support programmes for street children and sex trade workers. Injecting drug users have been working to produce programmes but have yet to mount

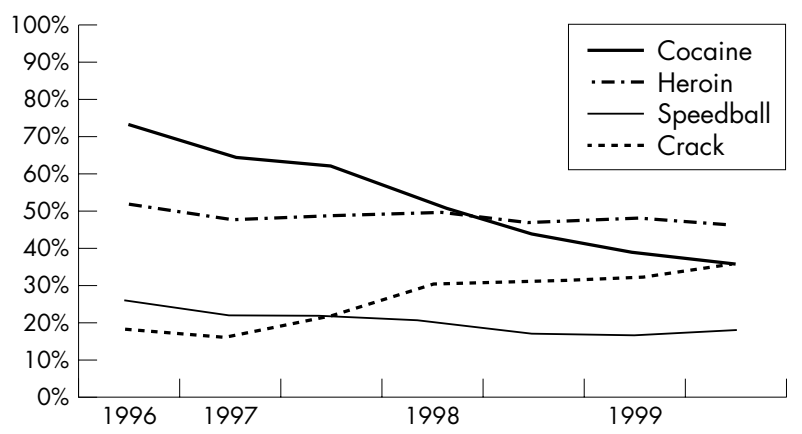

Figure 1 Trends in drugs used at least weekly, Vancouver injection drug user study. 


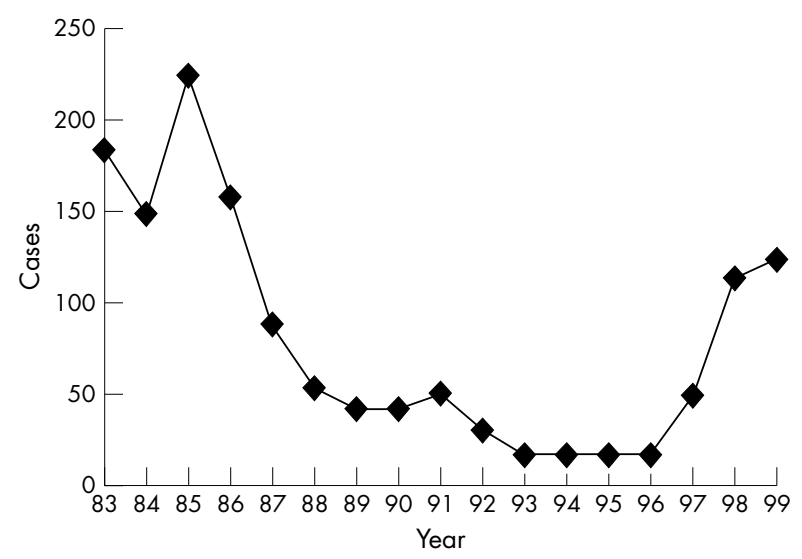

Figure 2 Annual number of cases of infectious syphilis, British Columbia, 1983-99.

Table 2 Rate of infectious syphilis by region (per 100000 population)

\begin{tabular}{llll}
\hline & 1997 & 1998 & 1999 \\
\hline British Columbia & 1.2 & 2.6 & 3.4 \\
Vancouver/Richmond & 5.4 & 12.6 & 12.9 \\
Adjacent municipalities & 0.6 & 1.2 & 2.6 \\
Vancouver's downtown eastside & 53 & 123 & 126 \\
Rest of British Columbia & 0.1 & 0.1 & 0.3 \\
\hline
\end{tabular}

sustained effective peer intervention efforts. Thus most outreach work is by people not currently addicted to injection drugs.

Separate government ministries manage addiction and other health services. This separation of responsibility has not facilitated coordination between communicable disease control efforts and various addiction services. The practice of issuing all welfare payments on a single Wednesday every two weeks has led to a "Mardigras"-like phenomenon in which there is a high concentration of drug consumption and sex trade activity over the day or two after cheques have been issued.

\section{Behaviour}

Of clients attending the local STD outreach clinic during 1998, only $25 \%$ reported using condoms always, whereas $49 \%$ reported inconsistent use and $24 \%$ reported no use. ${ }^{1}$ Sixty six per cent of injection drug using women in the VIDUS study reported 20 or more lifetime partners, with $49 \%$ reporting 100 or more.

Among the large drug using population in the downtown eastside, significant changes in drug use patterns were occurring before and during the syphilis outbreak. The trends in drugs used at least weekly between 1996 and 1999 are shown in fig l. It is notable that, while weekly use of injection cocaine declining from $73 \%$ to $36 \%$ of users, the use of crack cocaine increased from $18 \%$ to $36 \%$ of users between 1996 and 1999 .

\section{Descriptive epidemiology}

Between 1996 and 1999, the rate of infectious syphilis increased over sixfold from 0.5 per 100000 to 3.4 per 100000 population in British Columbia. The impact on the annual case count is shown in fig 2. In all, 277 cases were reported in the 30 months between July 1997 and December 1999. In the downtown eastside neighbourhood of Vancouver, the rate reached 126 per 100000 population (table 2 ).

Figure 3 shows the distribution of the 99/220 Vancouver cases for whom postal code data were available. The heaviest concentration is in the downtown eastside area. Two other concentrations are visible at the sites of STD clinics and physicians' offices. Fewer cases are located in the greater Vancouver region.

Men comprised $54 \%$ of the cases. Cases were most frequent among 30 to 49 year old men and 20 to 39 year old women (fig 4 ). Whites accounted for $35 \%$ of cases, aboriginals $22 \%$, Asians $13 \%$, Hispanics $8 \%$, south Asians 6\%, blacks 3\%, and unascertained $14 \%$ (table 3 ).

The outbreak of infectious syphilis was principally transmitted heterosexually. Fully $42 \%$ of cases were directly linked to the sex trade ( $24 \%$ sex trade clients, $18 \%$ sex trade workers). Thirteen per cent were street-involved (street youngsters and

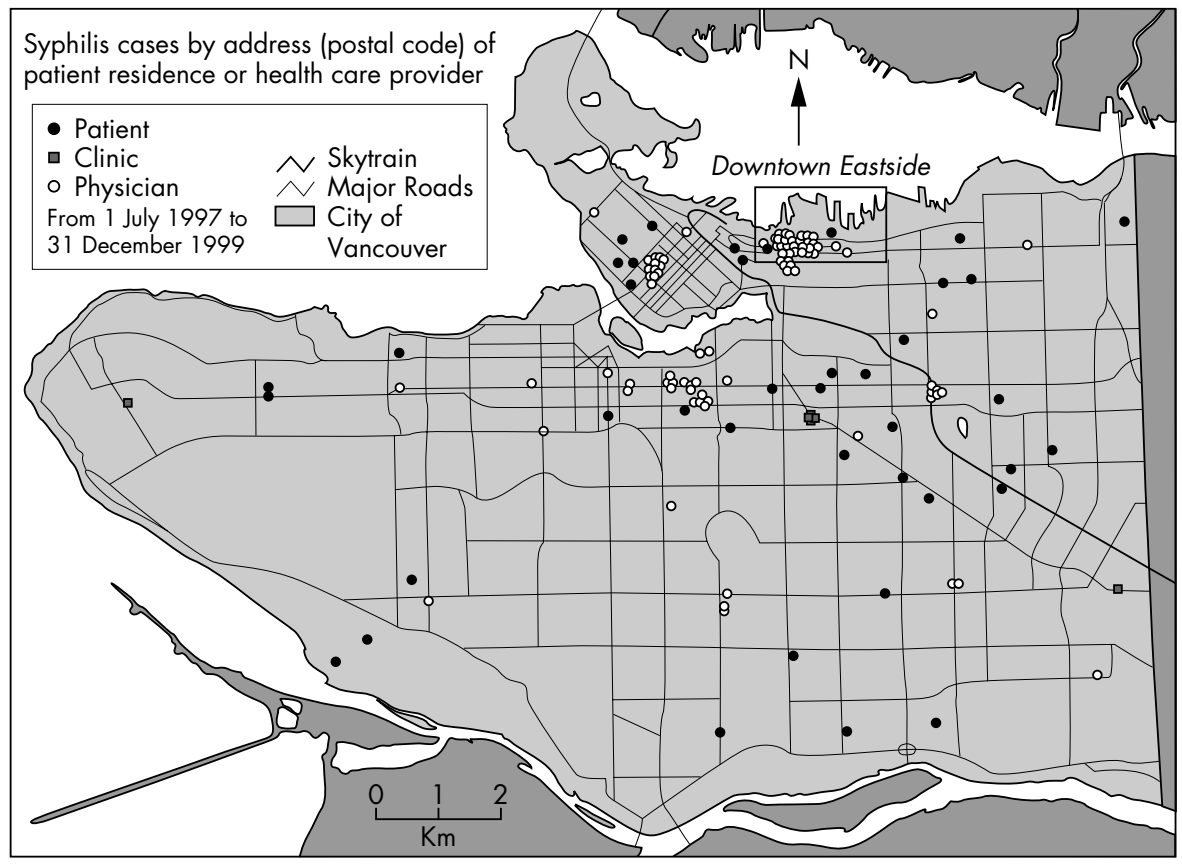

Figure 3 Distribution of infectious syphilis in the city of Vancouver. 


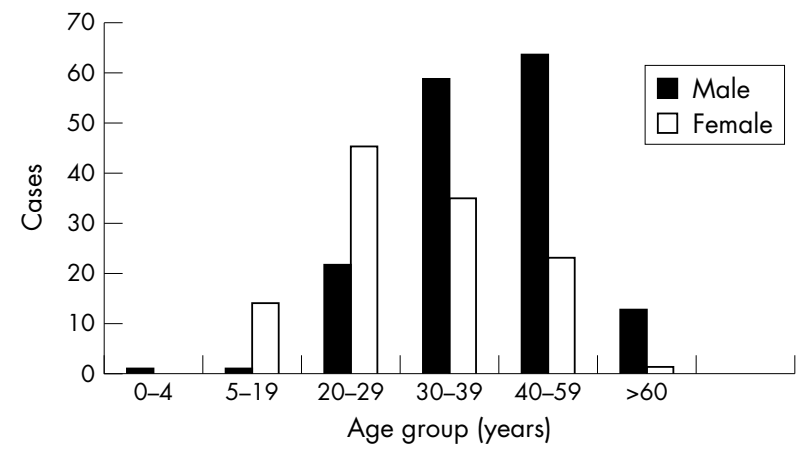

Figure 4 Infectious syphilis by age and sex.

\begin{tabular}{|c|c|}
\hline \multicolumn{2}{|l|}{ Sex } \\
\hline Male & $54 \%$ \\
\hline Female & $46 \%$ \\
\hline \multicolumn{2}{|l|}{ Ethnicity } \\
\hline White & $35 \%$ \\
\hline Aboriginal & $22 \%$ \\
\hline Asian & $13 \%$ \\
\hline Hispanic & $8 \%$ \\
\hline South Asians & $6 \%$ \\
\hline Blacks & $3 \%$ \\
\hline Not recorded & $14 \%$ \\
\hline \multicolumn{2}{|l|}{ Risk factors } \\
\hline Sex trade clients & $24 \%$ \\
\hline Sex trade workers & $18 \%$ \\
\hline Street-involved & $13 \%$ \\
\hline Foreign exposure & $16 \%$ \\
\hline Gay male & $6 \%$ \\
\hline Casual heterosexual contact & $14 \%$ \\
\hline Other/unknown & $9 \%$ \\
\hline
\end{tabular}

injection drug users), 16\% reported foreign exposure (Asia and Central America); $6 \%$ were gay males with anonymous sexual contacts in bathhouses; $14 \%$ reported casual heterosexual contact; $7 \%$ were in other risk categories such as female spouses with only one sexual partner; and for $2 \%$ the risk was unknown. Many in the casual risk and street-involved categories were believed to be "non-paying" sexual contacts of sex trade workers-pimps, pushers, and boyfriends who often did not use condoms.

Many of the cases in adjacent municipalities involved the clients of sex trade workers. In three documented instances, these clients had infected spouses. There were two cases of congenital syphilis, both occurring during the first year of the outbreak.

\section{Partner notification}

Partner notification during the outbreak often met with difficulty because index cases were unable or unwilling to name their sexual partners. Public health nurses who are given the responsibility for contact tracing reported that index cases were frequently unable to assist because of mental illness or drug addiction. Among people with infectious syphilis, 277 cases named 429 partners, a mean of 1.6 named partners per case (range 0 to 21 ). Only 232 of the 429 partners were documented as having been treated ( $54 \%$ of those named, or 0.9 per case).

\section{Sexual networks as inferred from case contact data}

Network analysis used data on cases diagnosed from March 1997 until October 1999, and their contacts. One hundred and fifteen networks were constructed from 398 cases and
Table 4 Frequency distribution of cases, contacts, and networks: syphilis outbreak, British Columbia, Canada, March 1997 to October 1999

\begin{tabular}{llll}
\hline Network size & $\begin{array}{l}\text { Number of } \\
\text { networks }\end{array}$ & $\begin{array}{l}\text { Per cent of } \\
\text { total networks }\end{array}$ & $\begin{array}{l}\text { Per cent of } \\
\text { people }\end{array}$ \\
\hline 1 & 97 & 45.8 & 24.4 \\
2 & 80 & 37.8 & 40.2 \\
3 & 21 & 9.9 & 15.8 \\
4 & 7 & 3.3 & 7.0 \\
5 & 3 & 1.4 & 3.8 \\
7 & 1 & 0.5 & 1.8 \\
8 & 1 & 0.5 & 2.0 \\
9 & 1 & 0.5 & 2.3 \\
11 & 1 & 0.5 & 2.8 \\
\hline
\end{tabular}

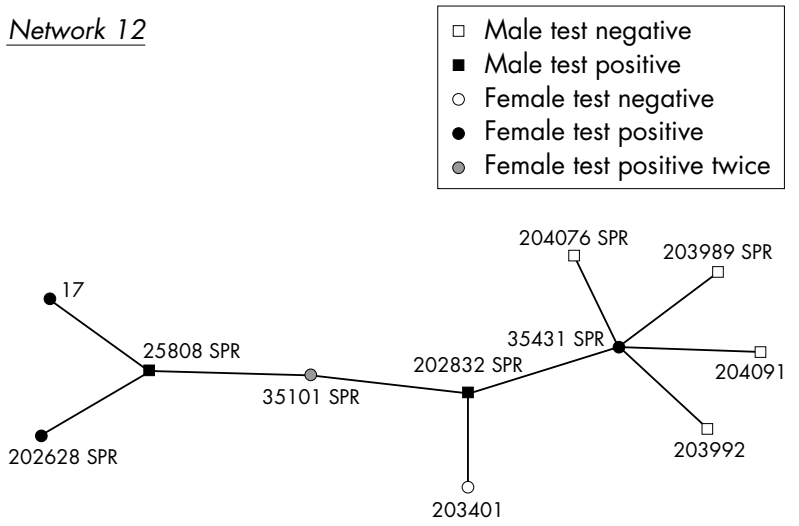

Figure 5 A dendritic sexual network associated with the sex trade.

contacts. There were 97 people who had no named partners ( $46 \%$ of all networks), and 101 people in the $48 \%$ of networks containing two or three people (table 4) There were 14 networks of four of more people, representing $7 \%$ of all the networks found and containing $20 \%$ of all cases and contacts. The three types of network identified were: imported cases with secondary spread (dyads and triads); networks of sex trade workers and clients which were larger, dendritic, and more densely connected (fig 5); and gay men with bathhouse contact, also large but showing one central case surrounded by many contacts, none of whom were interconnected (starburst pattern). Although intuitively one would expect the presence of recursive networks (networks which feed back upon themselves) in this setting, none were documented. Three of the larger networks were linked to index cases diagnosed in the three months before the outbreak became obvious in July of 1997. In the largest networks of five or more people, times between the diagnosis of the first case and the last ranged from 2 to 50 weeks.

\section{Trends for other sexually transmitted infections}

Concurrently with the syphilis outbreak, gonorrhoea rates also increased in British Columbia. Review of gonorrhoea cases showed a moderate overlap with the population affected by syphilis. There have also been small increases in reports of genital chlamydia infection in 1998 and 1999 (fig 6).

There were 15 new HIV infections during the 30 month period described here among men for whom sex trade worker contact had been the primary risk. There were no such cases in the years before 1997. HIV and hepatitis C incidence has been directly measured among a cohort of injecting drug users in the downtown eastside. HIV incidence has declined from $18.6 \%$ during 1996/97 to between 3\% and 5\% during recent follow up. Hepatitis C incidence has remained near $20 \%$ over 3.5 years of follow up. ${ }^{8}$ 


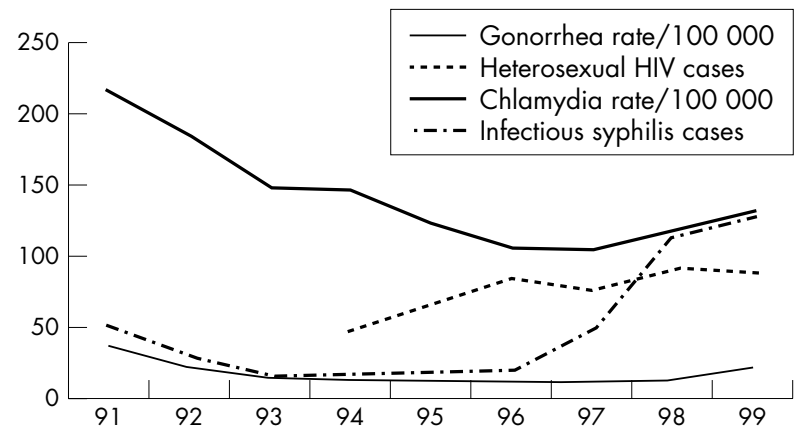

Figure 6 Trends for sexually transmitted infections in British Columbia.

\section{Interventions for the syphilis outbreak}

Enhancement of several public health control measures was tried but had not controlled the epidemic to December 1999. Public messages regarding the outbreak were widely disseminated through mainstream media. Numerous street level announcements in plain language were disseminated by public health and community agencies. Local providers were alerted to the outbreak and urged to increase the diagnostic focus on syphilis. Outreach workers offered serological testing for syphilis to sex trade workers and others at local drop-ins, bars, and hotels. Thus, enhanced contact tracing, education, and intensified diagnostic, screening, and treatment services had been implemented for 30 months to no avail. Sexual network mapping underscored the diminished ability to identify partners as an important barrier to current strategies to terminate the outbreak.

\section{DISCUSSION}

Upon a background of little or no endemic transmission, Vancouver experienced a sustained outbreak of infectious syphilis, beginning in July 1997. A persistently increased rate of infectious syphilis was of concern for several reasons. First, co-infection with syphilis could facilitate transmission of HIV within the downtown population, causing rates to rise yet again. ${ }^{9}$ Also, syphilis could facilitate the spread of HIV from affected drug-using sex trade workers to both the homosexual and the heterosexual populations of the province. Spread of infectious syphilis to men who have sex with men would then increase the risk of an associated rebound in HIV incidence. Given the mobility of people in Vancouver downtown eastside across Canada, spread to other provinces was also a serious consideration. Finally, this single outbreak substantially impedes Canadian progress toward eliminating endemic syphilis.

It seems probable that infectious syphilis was initially imported into the downtown eastside neighbourhood, where it gained a foothold when it contacted sexual networks with characteristics that supported further propagation.

A pattern of infectious syphilis transmission in association with increasing crack cocaine use and the sex trade has been well described. ${ }^{10}$ The need for female drug users to work in the sex trade to support their habit, combined with the chaotic sexual behaviour associated with crack or injection cocaine use, favours the formation of densely connected sexual networks with high rates of concurrent partnership. Such networks are highly suited to the rapid spread of an efficiently transmitted STD such as infectious syphilis. If they also contain members with little ability to assist with partner notification and treatment, they also represent an ecological niche for Treponema pallidum, where it may spread with a degree of protection from standard public health practices.

Contact tracing in such a scenario can be difficult. Even when there is no impairment of mental status from drug use, sex trade workers may be unable to name contacts owing to the anonymous nature of sex trade transactions. ${ }^{11}$

There is growing interest in the potential application of sexual network analysis to focusing health interventions for STIs. We observe that this approach may be limited by the quality of available case contact data. As $46 \%$ of cases named no contacts, our inability to demonstrate recursive sexual networks may be explained by incomplete information rather than by true network configuration. Further study may determine whether ethnographic and qualitative approaches to data collection can provide a timely and instructive insight into assisting planning.

The one feature of the outbreak that conceivably represented an Achilles heel was its intense geographical and demographic concentration. While cases from outside the downtown eastside were spreading infectious syphilis to partners, networks with the characteristics required to actually sustain endemic transmission seemed largely confined to identifiable groups in one neighbourhood. Furthermore, available information suggested a central role for sex workers and their clients in sustaining disease activity.

\section{Phase specific interventions}

Sexually transmitted disease epidemics have been described as dynamic interactions among the pathogen, behaviour, and preventive efforts that evolve through predictable phases. ${ }^{12}$ Within this model, phase IV describes low level endemic transmission among core transmitter groups which sustain the disease within an area and which is especially difficult to tackle with traditional public health control strategies. In fact, Canada's goals for syphilis control initially reflected the likelihood that reductions below the level of 0.5 per 100000 would be difficult to maintain in the absence of global efforts. ${ }^{13}$ Outbreaks against this background of endemic transmission may occur from time to time and may involve sexual networks with some difficult characteristics. These characteristics are likely to include a high rate of sexual contact, high concurrency of sexual partnerships, poor health care utilisation, high density, and poor overlap with social networks through which prevention efforts could disseminate. This theoretical description matches well with the ethnographic description observed in downtown Vancouver.

Aside from partner notification and treatment, several strategies have been described as useful during phase IV of an STD epidemic. Most of these have been employed in Vancouver. Media messages may have had limited effect because they are most accessible only to those on the margins of the maintenance sexual networks, such as suburban dwelling sex trade clients. Targeted plain language announcements disseminated by outreach workers make for better penetration, but educational messages alone may prove insufficient to alter behaviour among those driven by addiction, economic need, or the control of a pimp.

Serological screening of sex workers at local drop-ins, bars, and hotels, as well as STD outreach diagnostic services, did not yield many occult cases. This may be explained by the generally low prevalence even in the context of this outbreak, and by the likelihood that the most marginalised and affected sex workers are less visible in drop-ins and public venues. Another suggested phase IV approach-peer risk reduction counselling-has played only a limited role to date because of the profound effects of addiction on the abilities of potential peer workers and on the efficacy of behavioural counselling.

Focused mass or presumptive treatment is a potentially effective strategy that is based on treating individuals with high risk group membership and not only those with a clear history of exposure. The strategy is not often considered feasible and has only rarely been attempted. Where employed, it has generally been used over broader geographical areas for populations with a high prevalence of the target pathogen. For 
example, focused mass treatment has proven effective for non-venereal treponematoses. ${ }^{14}$

Though Vancouver's downtown eastside cannot be classified as a high prevalence setting by world standards, the localisation of the outbreak and its involvement of fairly well demarcated groups-for example sex trade workers and clients-led to consideration of a small scale focused mass treatment approach. The approach has been applied during two other outbreaks of infectious syphilis in North America. ${ }^{15} 16$

Recently, the availability of animal and human data on the efficacy of azithromycin against incubating and infectious syphilis, ${ }^{17-21}$ together with experience with the safety of the drug in the Rakai district of Uganda, ${ }^{22}$ raised the prospect of considering mass treatment with an oral antibiotic.

The success of such an effort in Vancouver would ultimately depend both on the coverage of the high risk group within the geographical area and on the risk of reintroduction of syphilis from outside. The existence of an engaged and credible street outreach nursing service with connections to the affected demographic groups made it possible to conceive a focused mass treatment approach in Vancouver's downtown eastside. The fact that very low rates of infectious syphilis had previously been sustained for half a decade in British Columbia suggested that reintroduction may not necessarily be immediate, and that there may be a prospect of a sustained benefit should an initial effort proved successful.

A subsequent report from our group will describe the implementation and evaluation of such an initiative.

\section{ACKNOWLEDGEMENT}

This work was supported by special funding from the British Columbia Ministry of Health and from Health Canada.

\section{Authors' affiliations}

D M Patrick, M L Rekart, S Mak, J Maginley, H Jones, C

Montgomery, R C Brunham, University of British Columbia Centre for Disease Control, Vancouver, Canada

A Jolly, E Wong, T Wong, Bureau of HIV/AIDS, STD and TB, Health Canada, Ottawa, Canada

M Tyndall, British Columbia Centre for Excellence in HIV/AIDS

Vancouver, Canada

\section{REFERENCES}

1 British Columbia Centre for Disease Control. Sexually transmitted disease control, annual report, 1999. Vancouver: British Columbia Centre for Disease Control Society, 1999
2 Patrick DM, Strathdee SA, Archibald CP, et al. Determinants of HIV seroconversion in injection drug users during a period of rising prevalence in Vancouver. Int J STD AIDS 1997;8:437-45.

3 Jones HD, Knowles LJ, Patrick DM, et al. STD Information System: a computerized STD clinical record and reporting system. Abstract presented at International Society for STD Research, New Orleans, June 1995.

4 Strathdee SA, Patrick DM, Currie SL, et al. Needle exchange is not enough: lessons from the Vancouver injecting drug use study. AIDS 1997;11:F59-65.

5 Statistics Canada. Census of population. Ottawa: Canada, 1996.

6 LCDC. Consortium to characterize injection drug users in Canada. Final report. Toronto: Department of Public Health Sciences, Faculty of Medicine, University of Toronto, 1998.

7 Currie S, Tyndall M, Lachance N, et al. Policy meets practice: the impact of monthly welfare payments on drug use and risk behaviors among injection drug users. Canadian Association for HIV Research Meeting Montreal, 2000.

8 Patrick DM, Tyndall M, Cornelisse PGA, et al. The incidence of hepatitis $C$ virus infection among injecting drug users during an outbreak of HIV infection. Can Med Assoc J (in press).

9 Wasserheit JN. Epidemiological synergy; interrelationships between human immunodeficiency virus and other sexually transmitted diseases. Sex Transm Dis 1992;19:61-77.

10 Gunn RA, Montes JM, Toomey KE, et al. Syphilis in San Diego County 1983-1992: crack cocaine, prostitution, and the limitations of partner notification. Sex Transm Dis 1995;22:60-6.

11 Potterat JJ, Rothenberg R, Bross DC. Gonorrhea in street prostitutes: epidemiologic and legal implications. Sex Transm Dis 1979;6:58-63.

12 Wasserheit JN, Aral SO. The dynamic topology of sexually transmitted disease epidemics: implications for prevention strategies. J Infect Dis 1996; 174(suppl 2):S201-13.

13 Romanowski R. National goals for the prevention and control of sexually transmitted diseases in Canada: syphilis. Can Commun Dis Rep 1997;23S6(suppl).

14 Grin El, Guthe T. Evaluation of a previous mass campaign against endemic syphilis in Bosnia and Herzegovina. Br J Vener Dis 1973;49:1-19

15 Jaffe HW, Rice DT, Voigt R, et al. Selective mass treatment in a venereal disease control program. Am J Public Health 1979:69:1181-2.

16 Hibbs JR, Gunn RA. Public health intervention in a cocaine-related syphilis outbreak. Am J Public Health 1991;81:1259-62.

17 Stamm LV, Parris EA. In-vitro activity of azithromycin and CP-63,956 against Treponema pallidum. J Antimicrob Chemother 1990;25(suppl A): 11-14.

18 Lukehart SA, Fohn M, Baker-Zander SA. Efficacy of azithromycin for therapy of active syphilis in the rabbit model. J Antimicrob Chemother 1990:25(suppl A):91-9.

19 Hook EW, Stephens J, Ennis DM. Azithromycin compared with penicillin $G$ benzathine for treatment of incubating syphilis. Ann Intern Med 1999;131:434-7

20 Verdon MS, Handsfield HH, Johnson RB. Pilot study of azithromycin for treatment of primary and secondary syphilis. Clin Infect Dis 1994;19:486-8.

21 Mashkilleyson AL, Gomberg MA, Mashkilleyson N, et al. Treatment of syphilis with azithromycin. Int J STD AIDS 1996;7(suppl 1):13-15.

22 Wawer MJ, Sewankambo NK, et al. Control of sexually transmitted diseases for AIDS prevention in Uganda: a randomized community trial. Lancet 1999;353:525-35. 